\title{
Prevalence of human papillomavirus infection and type distribution among Uyghur females in Xinjiang, northwest China
}

\author{
XIAOLONG YAN, YAN HUANG, MEI ZHANG, XIN HU, KE LI and MINGXIA JING \\ Department of Preventive Medicine, Medical College of Shihezi University, Shihezi, Xinjiang 832002, P.R. China
}

Received January 16, 2020; Accepted May 27, 2020

DOI: $10.3892 / 01.2020 .11886$

\begin{abstract}
Human papillomavirus (HPV) infection has a key role in the development of cervical cancer. The present study aimed to determine the HPV type distribution among females of Uyghur ethnicity in Xinjiang province, northwest China. A total of 12,165 individuals aged 30-79 years from 12 villages in Zepu County, Kashgar Prefecture, Xinjiang province were recruited for screening. Cervical and vaginal swabs from each subject were collected by gynecologists and tested for HPV DNA using Luminex xMAP technology. The results indicated that the overall HPV prevalence was $9.34 \%(1,136 / 12,165)$ in the present cohort; $7.41 \%(901 / 12,165)$ of the individuals were positive for high-risk type HPV (HR-HPV) and 1.64\% (200/12,165) were positive for multiple types. Among the individuals who tested positive for HR-HPV types, the three most prevalent types were HPV16 (2.83\%), HPV31 (0.99\%) and HPV68 $(0.88 \%)$. Subgroup analysis by age indicated that the highest frequency of HPV infections occurred in subjects aged $>60$ years. The most common genotype combinations in subjects with multiple types were HPV16 + HPV54, HPV16 + HPV31 and HPV16 + HPV68. The present study provided data on the prevalence and type distribution of HPV infections among Uyghur females in Xinjiang province, northwestern China, which will assist in the assessment of the potential cost-effectiveness of HPV screening and vaccination in this population. The data will also facilitate the determination of HPV68 and 54 strains that should be included in the multi-type vaccine and the establishment of a vaccination program that caters for the different age groups of the Uyghur population.
\end{abstract}

Correspondence to: Dr Mingxia Jing, Department of Preventive Medicine, Medical College of Shihezi University, 107 Hongshan Road, Shihezi, Xinjiang 832002, P.R. China

E-mail: jingmingxia126@126.com

Key words: human papillomavirus, prevalence, genotyping

\section{Introduction}

Cervical cancer is the second most common type of gynecological cancer in developing countries, with incidence and mortality rates only second to breast cancer in China (1). In 2018, there were 106,000 novel cases of cervical cancer and 33,000 mortalities in China (2). Human papillomavirus (HPV) has been proven to be the cause of numerous reproductive tract diseases and is the major cause of cervical cancer $(3,4)$. According to the risk degree of tumor occurrence associated with infection with various strains of HPV, these strains may be divided into high-risk (HR-HPV) and low-risk (LR-HPV) types. In particular, persistent infection with HR-HPV is the major cause of cervical cancer and oropharyngeal cancer (5), while LR-HPV infection mainly leads to genital warts (4).

As HPV has an important role in the natural etiology of cervical cancer, HR-HPV screening is more sensitive and cost-effective than other screening methods (6). In recent years, large-scale vaccination projects have been performed in numerous countries and the preventive effect of HPV vaccines on HPV-associated diseases has been confirmed in various studies $(7,8)$. In 2014, Gardasil 9, a vaccine that protects against HPV6, 11, 16, 18, 31, 33, 45, 52 and 58, was approved by the US Food and Drug Administration and its application was launched. However, Gardasil 9 does not cover all HR-HPV types that may lead to cervical cancer and the prevalence of HPV types is affected by geography, with a certain degree of variation in different countries and regions (9).

In China, although certain studies have been performed to assess the prevalence and incidence rates of HPV genotypes in Yunnan, Henan and Qingdao, most of them are based on small samples (10-12). Xinjiang Province, located in the northwestern part of China, is relatively undeveloped from an economical and cultural perspective. There is a large Uygur population in this region and the HPV distribution reported in previous studies was only investigated in small numbers of subjects (13). However, no previous survey has performed any large-sample screening in this population.

Therefore, it is necessary to investigate the prevalence and type distribution of HPV in Uyghur females in Xinjiang Province, northwest China. In the present study, a larger sample size $(12,165)$ of the population was screened to assess the prevalence and type distribution of HPV infection in 
Xinjiang. The present results will contribute to the evaluation of the potential cost-effectiveness of HPV screening and vaccination in Xinjiang province.

\section{Materials and methods}

Study population. The present study included females in 12 villages in Zepu county, Xinjiang Province. A total of 12,165 Uyghur females attended the Maternal and Child Health Hospital and outpatient clinics and expressed their willingness to undergo cervical cancer screening between January 2015 and December 2017. Subjects were included if they met the following criteria: i) History of sexual activity; no current pregnancy, menstruation and lactation; ii) no history of hormone therapy in the past 6 months; iii) no history of cancer; iv) no history of cervical surgery, radiotherapy or chemotherapy; and v) no history of treatment for HPV infection.

HPV-DNA testing. A total of 12,165 samples were tested by the HPV Liquid Bead Microarray (CapitalBio Medical Laboratory Center), which is able to detect 18 types of HR-HPV $(16,18,31$, $33,35,39,45,51,52,53,56,58,59,66,68,73,82$ and 83$)$ and 10 types of LR-HPV $(6,11,40,42,43,44,54,61,70$ and 81$)$.

Instruments and reagents. A Luminex 200 multi-function flow matrix (Thermo Fisher Scientific, Inc.), Mastercycler Gradient gene amplification instrument (Eppendorf) were used in the present study. The DNA extraction, PCR amplification, bead-coated hybridization, digital signal processing, biotin universal primers, biotin marking $\beta$-globin PCR primers (Table SI), and Luminex suspension beads and floating microsphere hybridization probe were provided by Tellgen Corporation.

Cervical specimen collection. The cervical exfoliated cells of the included women were collected by the clinician using a specialized cervical brush. Each cervical specimen was placed in $2.5 \mathrm{ml}$ of a sampling tube with a special cell preservation solution (Tellgen Corporation). All samples were delivered to the laboratory at $-20^{\circ} \mathrm{C}$ and tested within $48 \mathrm{~h}$.

DNA extraction. The samples in the preservation solution were thoroughly mixed before $1 \mathrm{ml}$ of each sample was placed in a centrifuge tube. The supernatant was collected following centrifugation at $21,578 \mathrm{xg}$ for $5 \mathrm{~min}$ at $4^{\circ} \mathrm{C}$, and the nucleic acid was extracted using a nucleic acid extraction kit after washing with normal saline. Finally, the sample DNA was dissolved in $50 \mu \mathrm{l}$ elution buffer (Tellgen Corporation) and stored at $-20^{\circ} \mathrm{C}$.

Luminex liquid-phase chip primer design. The detection of HPV genotypes in tissues by Luminex liquid-phase chip technology was performed by PCR amplification using universal primers covering different HPV subtypes; these primers target the high-protection zone of HPV L1 fragments in samples. At the same time, to quantify the experimental process and minimize sampling and instrument errors, an internal control comprising $\beta$-globin PCR primers for the detection of the augmented $\beta$-globin gene was included.

HPV typing and hybridization assay. Multiple PCR flow hybridization was used to detect HPV infection in the DNA extracted from the samples, including 18 types of HR-HPV $(16,18,31,33,35,39,45,51,52,53,56,58,59,66,68,73$, 82 and 83$)$ and 10 types of LR-HPV $(6,11,40,42,43,44$, $54,61,70$ and 81). A total of $5 \mu 1$ of each extracted DNA sample was used for PCR amplification. PCR was performed at $94^{\circ} \mathrm{C}$ for $30 \mathrm{sec}$, then at $58^{\circ} \mathrm{C}$ for $30 \mathrm{sec}$ and at $72^{\circ} \mathrm{C}$ for $30 \mathrm{sec}$ for 5 cycles. Subsequently, PCR was performed at $94^{\circ} \mathrm{C}$ for $30 \mathrm{sec}$, then at $55^{\circ} \mathrm{C}$ for $30 \mathrm{sec}$ and $72^{\circ} \mathrm{C}$ for $30 \mathrm{sec}$ for 35 cycles, with a final extension at $72^{\circ} \mathrm{C}$ for $5 \mathrm{~min}$. PCR products obtained by the above methods were rapidly hybridized at $94^{\circ} \mathrm{C}$ for $5 \mathrm{~min}$ and at $48^{\circ} \mathrm{C}$ for $30 \mathrm{~min}$. Analyses of hybridization and its related data were performed using the Luminex 200 multi-functional streaming lattice system (Thermo Fisher Scientific, Inc.) and its corresponding $\mathrm{xPONENT}^{\circledast}$ data analysis software (version 3.1; Thermo Fisher Scientific, Inc.), respectively.

Statistical analysis. Statistical analyses were performed using SPSS version 22 for Windows (IBM Corp.) for the calculation of the overall and type-specific prevalence of HPV. All genotypes from single and multiple infections were computed individually. These data were stratified by age $(\leq 35,36-40$, $41-45,46-50,51-55,56-60$ and $\geq 61$ years). The $\chi^{2}$ test was used to compare the prevalence between different age groups. $\mathrm{P}<0.05$ (two-sided) was considered to indicate a statistically significant difference.

\section{Results}

Prevalence of HPV infection in Xinjiang province. A total of 12,217 individuals were initially considered and total of 12,165 individuals (average age, $44.55 \pm 7.41$ years) were included in subsequent analyses, after 52 individuals were excluded from further analysis due to lack of data on the HPV genotype. The prevalence of HPV infections is presented in Table I. Among the 12,165 individuals, the overall HPV-positive rate was 9.34\% $(1,136 / 12,165)$. The HR-HPV-positive rate was $7.41 \%$ (901/12,165). Among the HPV-positive females, 936 were positive for a single HPV type (936/1,136, $82.39 \%$ of HPV infections; $936 / 12,165,7.70 \%$ of all samples) and 200 were positive for multiple types (200/1,136, 17.61\% of HPV infections; $200 / 12,165,1.64 \%$ of all samples). In addition, $79.31 \%$ $(901 / 1,136)$ had HR-HPV infections, $15.32 \%(174 / 1,136)$ had LR-HPV infections and only $5.37 \%(61 / 1,136)$ had both HRand LR-HPV infections.

Age-specific prevalence of HPV infection. The age-stratified HPV DNA prevalence across the different age groups is presented in Table I. The prevalence of HPV infection was significantly different among the age groups $\left(\chi^{2}=41.574\right.$, $\mathrm{P}<0.001)$ and was highest in the $\geq 61$-year-old group $(14.81 \%$, 64/432). HPV-positive rates increased with age $\left(\chi^{2}=38.880\right.$, $\mathrm{P}<0.001)$. The HPV-positive rate was significantly higher in females aged 50 years and above $(12.07 \%, 289 / 2,394)$ than in females aged up to 50 years $\left(8.67 \%, 847 / 9,771 ; \chi^{2}=26.307\right.$, $\mathrm{P}<0.001)$. The prevalence of multiple HPV infections and frequency of HR-HPV infections were also highest in the $\geq 61$-year-old group $(6.02 \%, 26 / 432$ and $12.73 \%, 55 / 432)$. The prevalence of multiple HPV infections and the frequency of HR-HPV infections also increased with age $\left(\chi^{2}=16.485\right.$, 
Table I. Prevalence of HPV infection in different age groups.

\begin{tabular}{lcccccrrr}
\hline $\begin{array}{l}\text { Age group } \\
\text { (years) }\end{array}$ & $\begin{array}{c}\text { Mean age } \\
\text { (years) }\end{array}$ & Total (n) & $\begin{array}{c}\text { Single } \\
\text { infection }\end{array}$ & $\begin{array}{l}\text { Multiple } \\
\text { infection }\end{array}$ & $\begin{array}{c}\text { HR-HPV } \\
\text { infection }\end{array}$ & $\begin{array}{l}\text { LR-HPV } \\
\text { infection }\end{array}$ & $\begin{array}{c}\text { HR \& LR-HPV } \\
\text { infection }\end{array}$ & $\begin{array}{c}\text { Total } \\
\text { HPV-positive }\end{array}$ \\
\hline$\leq 35$ & $33.91 \pm 2.21$ & 1050 & $66(6.29)$ & $11(1.05)$ & $58(5.52)$ & $18(1.71)$ & $1(0.10)$ & $77(7.33)$ \\
$36-40$ & $38.16 \pm 1.42$ & 2954 & $200(6.77)$ & $41(1.39)$ & $180(6.09)$ & $47(1.60)$ & $14(0.47)$ & $241(8.16)$ \\
$41-54$ & $43.09 \pm 1.41$ & 3552 & $252(7.09)$ & $51(1.44)$ & $238(6.70)$ & $49(1.38)$ & $16(0.45)$ & $303(8.53)$ \\
$46-50$ & $47.80 \pm 1.45$ & 2215 & $191(8.62)$ & $35(1.58)$ & $183(8.26)$ & $30(1.35)$ & $13(0.59)$ & $226(10.20)$ \\
$51-55$ & $52.77 \pm 1.41$ & 1220 & $111(9.10)$ & $22(1.80)$ & $117(9.59)$ & $11(0.90)$ & $5(0.41)$ & $133(10.90)$ \\
$56-60$ & $57.87 \pm 1.45$ & 742 & $78(10.51)$ & $14(1.89)$ & $70(9.43)$ & $18(2.43)$ & $4(0.53)$ & $92(12.40)$ \\
$\geq 61$ & $63.45 \pm 2.32$ & 432 & $38(8.80)$ & $26(6.02)$ & $55(12.73)$ & $1(0.23)$ & $1(0.23)$ & $64(14.81)$ \\
Total & $44.55 \pm 7.41$ & 12165 & $936(7.69)$ & $200(1.64)$ & $901(7.41)$ & $174(1.43)$ & $61(0.50)$ & $1136(9.34)$ \\
\hline
\end{tabular}

Values are expressed as the mean \pm standard deviation or $\mathrm{n}(\%)$. HR, high-risk; LR, low-risk; HPV, human papillomavirus.

Table II. Prevalence of each HPV genotype.

\begin{tabular}{|c|c|c|c|}
\hline $\begin{array}{l}\text { HPV } \\
\text { genotype }\end{array}$ & $\begin{array}{c}\text { Positive } \\
\text { samples (n) }\end{array}$ & $\begin{array}{c}\text { Positive rate in } \\
12,165 \text { total } \\
\text { samples }(\%)\end{array}$ & $\begin{array}{c}\text { Proportion among } \\
\text { 1,136 HPV-positive } \\
\text { samples }(\%)\end{array}$ \\
\hline \multicolumn{4}{|l|}{ HR-HPV } \\
\hline 16 & 344 & 2.83 & 30.28 \\
\hline 18 & 32 & 0.26 & 2.82 \\
\hline 31 & 121 & 0.99 & 10.65 \\
\hline 33 & 16 & 0.13 & 1.41 \\
\hline 35 & 30 & 0.25 & 2.64 \\
\hline 39 & 60 & 0.49 & 5.28 \\
\hline 45 & 37 & 0.30 & 3.26 \\
\hline 51 & 62 & 0.51 & 5.46 \\
\hline 52 & 85 & 0.70 & 7.48 \\
\hline 53 & 17 & 0.14 & 1.50 \\
\hline 56 & 29 & 0.24 & 2.55 \\
\hline 58 & 49 & 0.40 & 4.31 \\
\hline 59 & 49 & 0.40 & 4.31 \\
\hline 66 & 59 & 0.48 & 5.19 \\
\hline 68 & 107 & 0.88 & 9.42 \\
\hline 73 & 6 & 0.05 & 0.53 \\
\hline 82 & 14 & 0.12 & 1.23 \\
\hline 83 & 10 & 0.08 & 0.88 \\
\hline \multicolumn{4}{|l|}{ LR-HPV } \\
\hline 6 & 34 & 0.28 & 2.99 \\
\hline 11 & 7 & 0.06 & 0.62 \\
\hline 40 & 10 & 0.08 & 0.88 \\
\hline 42 & 37 & 0.30 & 3.26 \\
\hline 43 & 7 & 0.06 & 0.62 \\
\hline 44 & 5 & 0.04 & 0.44 \\
\hline 54 & 119 & 0.98 & 10.48 \\
\hline 61 & 22 & 0.18 & 1.94 \\
\hline 70 & 4 & 0.03 & 0.35 \\
\hline 81 & 3 & 0.02 & 0.26 \\
\hline
\end{tabular}

All HPV genotypes from single and multiple infections were computed individually. HPV, human papillomavirus; HR, high-risk; LR, low-risk.
$\left.\mathrm{P}<0.001 ; \chi^{2}=4.619, \mathrm{P}=0.032\right)$. The increase in HPV prevalence was most pronounced in the groups aged 56-60 and $>60$ years. The prevalence of single HPV infections and LR-HPV infections was highest in the 56-60-year-old group (10.51\%, 78/742 and 2.43\%, 18/742), but LR-HPV and single HPV infections were lowest in the $\geq 61$ - and $\leq 35$-year-old groups, respectively.

Distribution and genotypes of HPV infections. The positive rate and the distribution of HPV infection are listed in Table II. The most common HR-HPV types were HPV16 (30.28\%), HPV31 (10.65\%), HPV68 (9.42\%) and HPV52 (7.48\%), and the most common LR-HPV types were HPV54 (10.48\%), HPV42 (3.26\%), HPV6 (2.99\%) and HPV61 (1.94\%).

Among the positive cases, the prevalence of each HR-HPV type was significantly different between the different age groups $\left(\chi^{2}=6.454, \mathrm{P}=0.011\right.$; Fig. 1). HPV16, 31, 68 and 52 were consistently the four most common types of HR-HPV in each age group. The prevalence of HPV16 was the highest in the $\geq 61$-year-old group, followed by the 51-55- and 56-60-year-old groups. The prevalence of HPV31 was the highest in the $\geq 61$-year-old group, followed by the 56-60- and 51-55-year-old groups. However, the prevalence of HPV52 was highest in the 56-60-year-old group, which was different from HPV16 and HPV31.

The prevalence of each type of LR-HPV was also significantly different between the different age groups $\left(\chi^{2}=12.991\right.$, $\mathrm{P}<0.001)$. The most common types were HPV54, 6, 42 and 61 in each age group. HPV54 was the most common type in all age groups except for the 51-55-year-old group. However, there was only a slight difference in the prevalence of the other three HPV types in each age group (Fig. 2).

Among the 200 cases positive for multiple HPV types, three genotypes exhibited comparatively higher positive rates: HPV16 (39.00\%), HPV31 (21.00\%) and HPV54 (20.50\%) (Fig. 3). Among the 200 individuals infected with multiple HPV types, 169 had dual infections (169/200, 84.50\%), 26 had triple infections $(26 / 200,13.00 \%)$ and 5 were infected with four or more types of HPV (5/200, 2.50\%). The most common combinations of genotypes were HPV16 + HPV54 $(n=30$, $15.00 \%)$, HPV16 + HPV31 $(n=16,8.00 \%)$ and HPV16 + HPV $68(n=12,6.00 \%)$ (Table SII). 


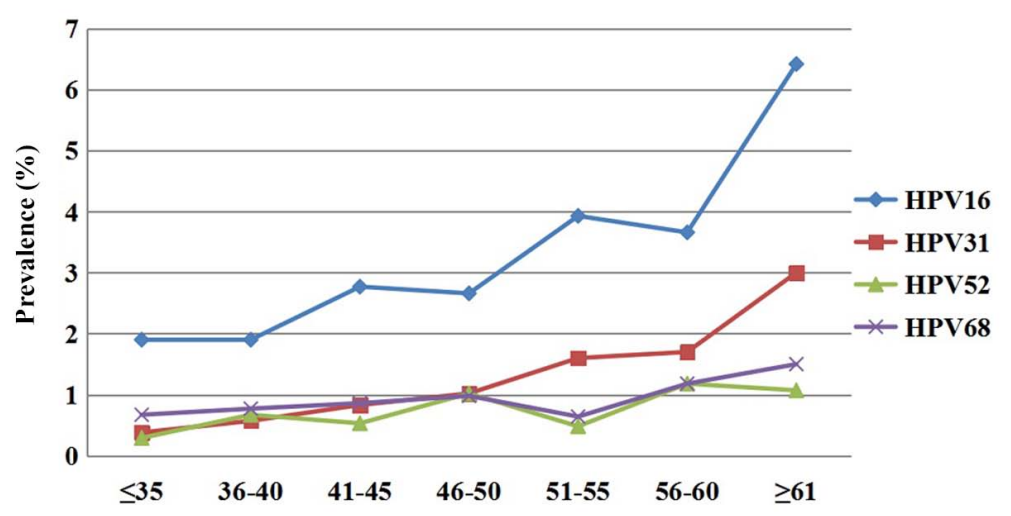

Figure 1. Prevalence of high-risk HPV genotypes (HPV16, 31, 52 and 68) in 7 different age groups. All HPV genotypes from single and multiple infections were plotted individually. Age is presented on the x-axis. HPV, human papillomavirus.

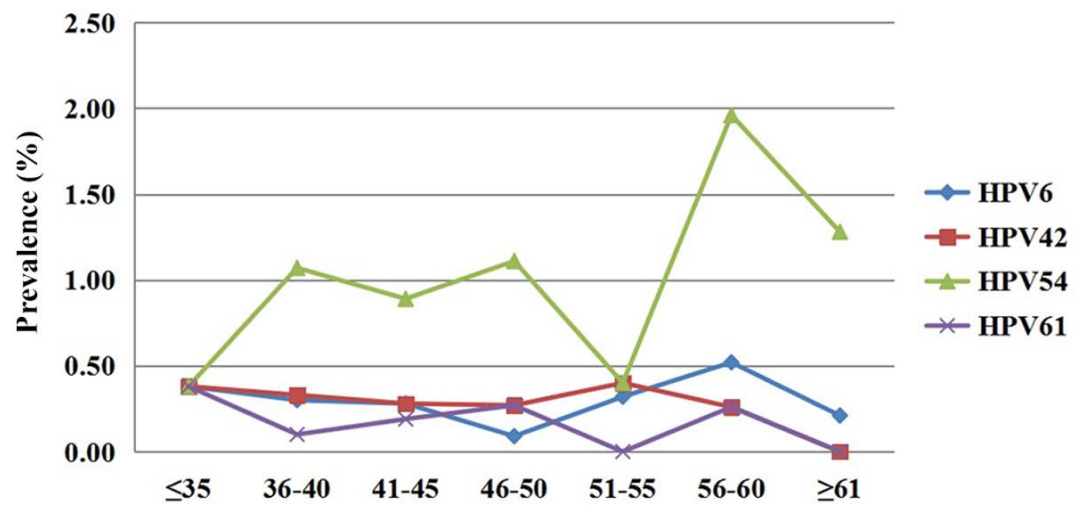

Figure 2. Prevalence of low-risk HPV genotype (HPV6, 42, 54 and 61) in 7 different age groups. All HPV genotypes from single and multiple infections were plotted individually. Age is presented on the $\mathrm{x}$-axis. HPV, human papillomavirus.

\section{Discussion}

HPV-DNA detection is of great importance for the screening and prevention of cervical cancer. However, cervical cancer screening started comparatively late in China and there is still a huge gap between China and certain developed countries in terms of screening, diagnosis and treatment (14). The distribution data of HPV genotypes in different regions are still not sufficiently comprehensive, particularly in remote areas in western China, and the molecular epidemiological data still require to be further improved to provide a scientific basis for the prevention, treatment and elimination of HPV infection-associated diseases.

In the present study, 28 common oncogenic HPV types were detected in the Xinjiang Uyghur Autonomous Region of China, each with a distinct distribution pattern. There were certain differences in the distribution of HPV infection rates and subtypes in different regions and studying these differences will be helpful in the prevention and treatment of HPV infection and the development of HPV vaccines.

The present study suggested that the total HPV infection rate in the female screening population was $9.34 \%$. The overall prevalence of HPV in different parts of China ranges from $7.23 \%$ (Chaozhou, South China) to $36.55 \%$ (Harbin, Northeast China) (15-17). The present results were similar to those for Ningxia, Shanxi, Qinghai and northwest Gansu
(7.67-9.03\%) (18), but lower than those of a previous study on a Xinjiang population (10.96\%) (13). The difference may be mainly due to the fact that the present study, which was based on a screening population, had a much larger sample size. With the increasing awareness of cervical cancer, numerous asymptomatic individuals participate in HPV screening and the prevalence of HPV determined in the present study is likely to be more reflective of the actual prevalence. In Asian countries, the prevalence of HPV varies from 1.60 to $14.26 \%$ in females without any cervical abnormalities (19). Furthermore, the prevalence of HPV may be affected by the type of recruitment (outpatient-based or screening-based), examination techniques and time interval for HPV-DNA test (20).

From the present results, an age-associated HPV infection prevalence curve was produced. The prevalence curve, whether representing total infections with HPV, multiple strains of HPV or HR-HPV, exhibited only one maximum, which was in females aged 61 years and above. Other studies have reported a bimodal age distribution, with a peak in females aged $\leq 20$ years and a second peak in females aged $>60$ years $(16,21-24)$. As the subjects who were screened for cervical cancer in this area were all $>30$ years old, it was not possible to determine the HPV infection rate in young females, which may be the reason why the peak previously reported in younger females was not observed. In fact, the 


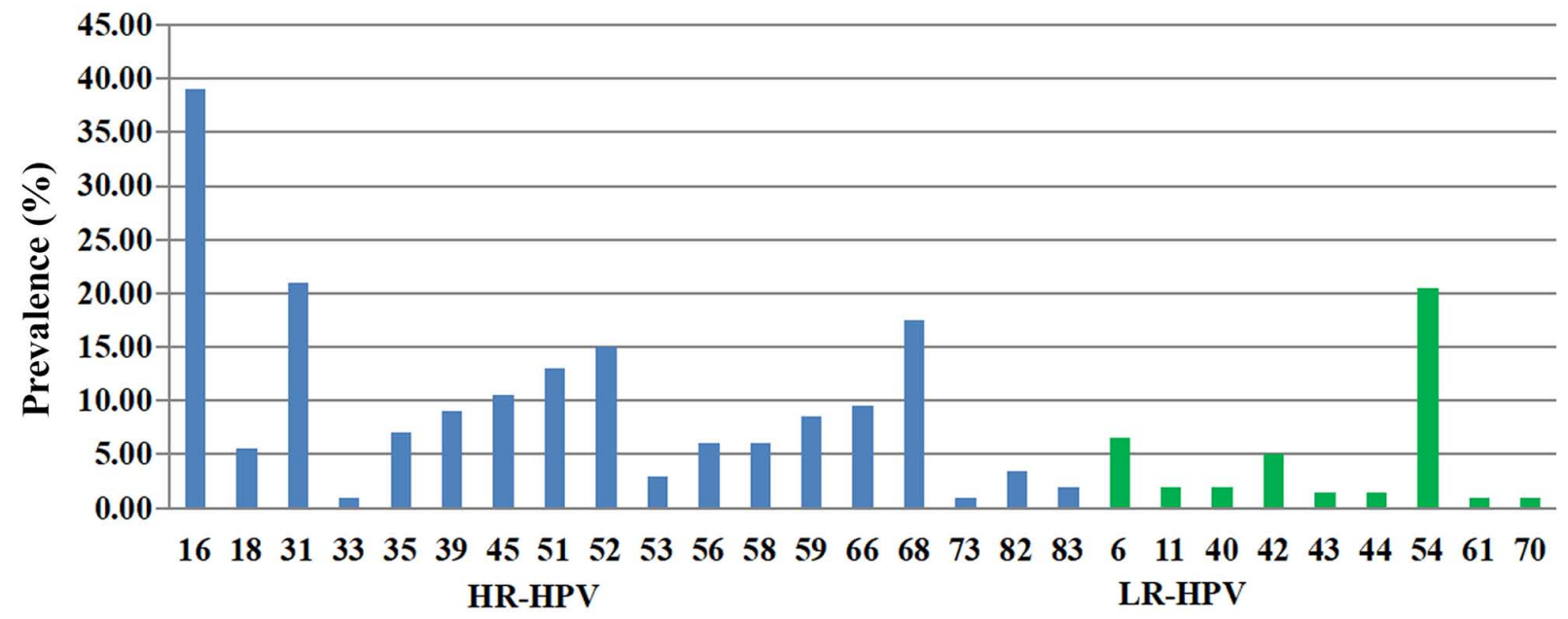

Figure 3. Prevalence of each HPV genotype in multiple infections. All genotypes from single and multiple infections were computed individually. HPV, human papillomavirus; HR, high risk; LR, low risk.

peak in younger females may be attributed to the fact that young females may have multiple sexual partners and also have less immunity to HPV infection (25). More attention should be paid to the second peak of HPV infection in females aged $>60$ years. The high rate of HPV infection in menopausal females may be due to the physiological and immune disorders caused by the persistence of the virus or the reactivation of latent HPV $(26,27)$. Therefore, HPV detection through cervical cancer screening programs holds clinical value for perimenopausal females. HPV-preventive vaccines yield more clinical benefits when vaccinated in early life (8). Thus, it is speculated that adolescent girls aged 13-15 years could benefit more than older women of HPV-infection status would from an HPV vaccination program in China (28).

The most common HR-HPV subtypes among females worldwide are HPV16, 18, 52, 31, 58, 33 and 51, although their prevalence varies by region (29). In the present study, the four most prevalent HR-HPV types were HPV16, 31, 68 and 52. Similar to the results of previous studies (15,30-32), HPV16 was the most common HR-HPV. However, the present results were different in that HPV31 and HPV52 were more common in the present cohort than HPV18. Another noteworthy point is that HPV68 was not common in Europe, North America and Australia $(29,33,34)$, but HPV68 was the third most prevalent strain in the present study, uncovering the unique distribution of HR-HPV in Uyghur females in Xinjiang. This suggests the regional diversity and dynamic changes characteristic of HPV infection and that HPV infection distributions may exhibit inhomogeneities among different ethnicities and regions. The samples of the present study were obtained from the Kashgar in southern Xinjiang, which has a large Uyghur population, and the sample size was relatively large; hence, the results obtained should be representative to a certain extent. Of note, Gardasil 9, which is a 9-valent HPV vaccine, was approved for use in China in 2018. Compared with the 2-valent and 4-valent HPV vaccines, the 9-valent HPV vaccine offers protection against $>90 \%$ of cervical cancers (35), thereby being able to prevent cervical cancer. The 9-valent vaccine targets high-risk HPV16, $-18,-52,-58$,
$-31,-33$ and -45 , as well as low-risk HPV6 and -11 . Due to the distribution of HPV genotypes exhibiting obvious regional differences, elucidation of the distribution of HR-HPV types in a specific region, as was performed in the present study, is conducive to targeted HPV vaccine development and clinical application.

Certain studies have indicated that infection with multiple HPV types has a significant impact on the duration of type-specific episodes and the development of cervical cancer. Fife et al (36) reported a correlation between the high incidence of cervical cancer and acquiring infection with multiple types of HPV. In addition, Torttier et al (37) indicated that co-infection increases the duration of infection. Perrons et al (38) reported that co-infection with HPV68 and -16 increased the risk of high-grade squamous intraepithelial lesions and cervical cancer compared to that with HPV16 alone or HPV68 alone. Due to its impact on the occurrence of cervical cancer, the prevalence of multiple HPV infections is of great significance in the prognosis of patients with persistent infection. The present study indicated that the proportion of multiple infections in HPV-positive females was 17.61\%, which was lower than that in Beijing (27.73\%) and Shanxi (24.31\%) (21). The most common genotype combinations in the present study population were HPV16 + HPV54 and HPV16 + HPV31, which are different from those determined by Zhao et al (39), namely HPV16 + HPV52 and HPV52 + HPV58.

There are several limitations to the present study. First, the study lacked information on the behavior of the enrolled individuals. Certain studies have indicated that behavioral factors may increase the risk of HPV infection and cervical cancer, but the lack of such information in the present study makes it difficult to analyze the effect of these potential exposure variables on the development of cervical cancer (40). In addition, the present study only focused on the distribution data of HPV genotypes in Xinjiang province. As no cytological data were collected from enrolled individuals; hence, the cytological classification of the cervical lesions was unknown, which may affect the baseline prevalence. In addition, due to the lack of samples from females below the 
age of 30 years, these results may not fully reflect the overall population of Uyghur females in Xinjiang. Furthermore, certain studies have reported that HPV infection may cause not only cervical cancer but oropharyngeal cancer and head and neck cancer (5), suggesting the requirement to focus on the association between HPV infection and oropharyngeal cancer and head and neck cancer in Uyghur females in future studies. In addition, the obtainment of data on HPV infection in Uyghur males was beyond the scope of the present study, while this may be considered as a potential direction for future research.

In conclusion, the present study revealed the distribution of different HPV types and the prevalence of HPV infection by genotypes with vaccines available for $>12,000$ Uyghur females in a screening population from Xinjiang province, northwest China. This information will help evaluate the potential cost-effectiveness of HPV screening and vaccination in Xinjiang. In addition, the present results have important implications for the development and application of HPV vaccines, suggesting that more HPV types (such as HPV68 and 54) should be considered for inclusion in the next generation of HPV vaccines.

\section{Acknowledgements}

Not applicable.

\section{Funding}

The present study was supported by the Science and Technology Plan Project of Xinjiang Production and Construction Corps (grant no. 2013BB015).

\section{Availability of data and materials}

The datasets used and/or analyzed during the present study are available from the corresponding author upon reasonable request.

\section{Authors' contributions}

$\mathrm{XY}$ and $\mathrm{MJ}$ were involved in the study conception and design. $\mathrm{XY}, \mathrm{XH}$ and $\mathrm{YH}$ collected and assembled the data. KL, XH and $\mathrm{MZ}$ were involved in data analysis and interpretation. $\mathrm{XY}$ drafted the initial manuscript. All authors read and approved the final manuscript.

\section{Ethics approval and consent to participate}

The study was approved by the ethics review committee of the Medical College of Shihezi University (Shihezi, China; approval no. 2015-058-01). Participating subjects provided written informed consent.

\section{Patient consent for publication}

Not applicable.

\section{Competing interests}

The authors declare that they have no competing interests.

\section{References}

1. Kim K, Zang R, Choi SC, Ryu SY and Kim JW: Current status of gynecological cancer in China. J Gynecol Onco 20: 72-76, 2009.

2. Arbyn M, Weiderpass E, Bruni L, de Sanjosé S, Saraiya M, Ferlay $\mathbf{J}$ and Bray F: Estimates of incidence and mortality of cervical cancer in 2018: A worldwide analysis. Lancet Glob Health 8: E191-E203, 2020.

3. Walboomers JM, Jacobs MV, Manos MM, Bosch FX, Kummer JA Shah KV, Snijders PJ, Peto J, Meijer CJ and Muñoz N: Human papillomavirus is a necessary cause of invasive cervical cancer worldwide. J Pathol 189: 12-19, 1999.

4. Forman D, Martel CD, Lacey CJ, Soerjomataram I, Lortet-Tieulent J, Bruni L, Vignat J, Ferlay J, Bray F, Plummer M and Franceschi S: Global burden of human papillomavirus and related diseases. Vaccine 30 (Suppl 5): F12-F23, 2012.

5. Jayaraj R, Kumarasamy C, Royam MM, Sabarimurugan S and Baxi S: Prognostic implications of pathologic lymph nodes in HPV-positive oropharyngeal cancers: Clinical validity and strategies for routine clinical practice. Oral Oncol 92: 99-100, 2019.

6. Zhao FH, Lin MJ, Chen F, Hu SY, Zhang R, Belinson JL Sellors JW, Franceschi S, Qiao YL and Castle PE; Cervical Cancer Screening Group in China: Performance of high-risk human papillomavirus DNA testing as a primary screen for cervical cancer: A pooled analysis of individual patient data from 17 population-based studies from China. Lancet Oncol 11: 1160-1171, 2010.

7. Wei L, Xie X, Liu J, Zhao Y, Chen W, Zhao C, Wang S, Liao X, Shou Q, Qiu Y, Qiao Y and Saah AJ: Efficacy of quadrivalent human papillomavirus vaccine against persistent infection and genital disease in Chinese women: A randomized, placebo-controlled trial with 78-month follow-up. Vaccine 37: 3617-3624, 2019.

8. Giuliano AR, Joura EA, Garland SM, Huh WK, Iversen OE, Kjaer SK, Ferenczy A, Kurman RJ, Ronnett BM, Stoler MH, et al: Nine-valent HPV vaccine efficacy against related diseases and definitive therapy: Comparison with historic placebo population. Gynecol Oncol 154: 110-117, 2019.

9. Jiang L, Tian X, Peng D, Zhang L, Xie F, Bi C, Wang R, Wang J and Qi D: HPV prevalence and genotype distribution among women in Shandong Province, China: Analysis of 94,489 HPV genotyping results from Shandong's largest independent pathology laboratory. PLoS One 14: e0210311, 2019.

10. Wang XC, Sun LQ, Ma L, Li HX, Wang XL, Wang X, Yun T, Meng NL and Lv D: Prevalence and genotype distribution of human papillomavirus among women from Henan, China. Asian Pac J Cancer Prev 15: 7333-7336, 2014.

11. Bi Q, Zhang L, Zhao Z, Mu X, Zhang $M$ and Wang P: Human papillomavirus prevalence and genotypes distribution among female outpatients in Qingdao, East China. J Med Virol 87: 2114-2121, 2015.

12. Li Z, Liu F, Cheng S, Shi L, Yan Z, Yang J, Shi L, Yao Y and Ma Y: Prevalence of HPV infection among 28,457 Chinese women in Yunnan Province, southwest China. Sci Rep 6: 21039, 2016.

13. Wang J, Tang DD, Wang K, Wang J, Zhang Z, Chen Y, Zhang X and Ma C: HPV genotype prevalence and distribution during 2009-2018 in Xinjiang, China: Baseline surveys prior to mass HPV vaccination. Bmc Womens Health 19: 90, 2019.

14. Rong-Min W, Jing-Jing P and Zhi-Xue Y: The Interpretation of 2012 ASCCP Management of Abnormal Cervical Cancer Screening Tests and Cancer Precursors(II). Journal of International Obstetrics and Gynecology 42, 2015.

15. Li J, Huang R, Schmidt JE and Qiao YL: Epidemiological features of Human Papillomavirus (HPV) infection among women living in Mainland China. Asian Pac J Cancer Prev 14: 4015-4023, 2013.

16. Chen Q, Xie LX, Qing ZR, Li LJ, Luo ZY, Lin M, Zhang SM, Chen WZ, Lin BZ, Lin QL, et al: Epidemiologic characterization of human papillomavirus infection in rural chaozhou, eastern guangdong province of China. PLoS One 7: e32149, 2012.

17. Sun B, He J, Chen X, He M, He Z, Wang Y, Shang Q, Yu L and Wei L: Prevalence and genotype distribution of human papillomavirus infection in Harbin, Northeast China. Arch Virol 159: 1027-1032, 2014

18. Cao BW, Yu JL, He H, Li ST and Zhao YL: Meta-analysis on the Relationship between HPV Infection and Esophageal Cancer in Chinese Population. J Capital Medical University 97: 148-150, 2010. 
19. Clifford GM, Gallus S, Herrero R, Muñoz N, Snijders PJ, Vaccarella S, Anh PT, Ferreccio C, Hieu NT, Matos E, et al: Worldwide distribution of human papillomavirus types in cytologically normal women in the International Agency for Research on Cancer HPV prevalence surveys: A pooled analysis. Lancet 366: 991-998, 2016.

20. Uusküla A,Kals M, Kosenkranius L, McNutt LA and DeHovitz JJ: Population-based type-specific prevalence of high-risk human papillomavirus infection in Estonia. BMC Infect Dis 10: 63, 2010.

21. Wu EQ, Liu B, Cui JF, Chen W, Wang JB, Lu L, Niyazi M, Zhao C, Ren SD, Li CQ, et al: Prevalence of type-specific human papillomavirus and pap results in Chinese women: A multi-center, population-based cross-sectional study. Cancer Causes Control 24: 795-803, 2013.

22. Jing L, Zhong X, Zhong Z, Huang W, Liu Y, Yang G, Zhang X, Zou J, Jing $C$ and Wei X: Prevalence of human papillomavirus infection in Guangdong Province, China: A population-based survey of 78,355 women. Sex Transm Dis 41: 732-738, 2014.

23. Wang R, Guo XL, Wisman GB, Schuuring E, Wang WF, Zeng ZY, Zhu $\mathrm{H}$ and Wu SW: Nationwide prevalence of human papillomavirus infection and viral genotype distribution in 37 cities in China. BMC Infect Dis 15: 257, 2015.

24. Wang CH, Garvilles RG and Chen CY: Characterization of human papillomavirus infection in north Taiwan. J Med Virol 82 $1416-1423,2010$

25. Torres-Poveda K, Ruiz-Fraga I, Madrid-Marina V, Chavez M and Richardson V: High risk HPV infection prevalence and associated cofactors: A population-based study in female ISSSTE beneficiaries attending the HPV screening and early detection of cervical cancer program. Bmc Cancer 19: 1205, 2019.

26. Althoff KN, Paul P, Burke AE, Viscidi R, Sangaramoorthy M and Gravitt PE: Correlates of cervicovaginal human papillomavirus detection in perimenopausal women. J Womens Health (Larchmt) 18: 1341-1346, 2009.

27. Kang LN, Castle PE, Zhao FH, Jeronimo J, Chen F, Bansil P, Li J, Chen W, Zhang X and Qiao YL: A prospective study of age trends of high-risk human papillomavirus infection in rural China. Bmc Infect Dis 14: 96, 2014

28. Chen R and Wong E: The feasibility of universal HPV vaccination program in Shenzhen of China: A health policy analysis. Bmc Public Health 19: 781, 2019.

29. de Sanjosé S, Diaz M, Castellsagué X, Clifford G, Bruni L, Muñoz N and Bosch FX: Worldwide prevalence and genotype distribution of cervical human papillomavirus DNA in women with normal cytology: A meta-analysis. Lancet Infect Dis 7: 453-459, 2007.

30. Sun LL, Jin Q, Li H, Zhou XR, Song ZQ, Cheng XM, Tao T, Liang B, Xu L, Wang YR, et al: Population-based study on the prevalence of and risk factors for human papillomavirus infection in Qujing of Yunnan province, Southwest China. Virol J 9: 153, 2012.
31. Argyri E, Papaspyridakos S, Tsimplaki E, Michala L, Myriokefalitaki E, Papassideri I, Daskalopoulou D, Tsiaoussi I, Magiakos G and Panotopoulou E: A cross sectional study of HPV type prevalence according to age and cytology. Bmc Infect Dis 13: $53,2013$.

32. Jiang Y, Brassard P, Severini A, Mao Y, Li YA, Laroche J, Chatwood S, Corriveau A, Kandola K, Hanley B, et al: The prevalence of human papillomavirus and its impact on cervical;dysplasia in Northern Canada. Infect Agent Cancer 8: $25,2013$.

33. Bouvard V, Baan R, Straif K, Grosse Y, Secretan B, El Ghissassi F, Benbrahim-Tallaa L, Guha N, Freeman C, Galichet L, et al: A review of human carcinogens-Part B: Biological agents. Lancet Oncol 10: 321-322, 2009.

34. Yoshikawa $\mathrm{H}$ : Progress and challenges on HPV vaccination. Uirusu 59: 243-248, 2009 (In Japanese).

35. Huh WK, Joura EA, Giuliano AR, Iversen OE, de Andrade RP, Ault KA, Bartholomew D, Cestero RM, Fedrizzi EN, Hirschberg AL, et al: Final efficacy, immunogenicity, and safety analyses of a nine-valent human papillomavirus vaccine in women aged 16-26 years: A randomised, double-blind trial. Lancet 390: 2143-2159, 2017.

36. Fife KH, Cramer HM, Schroeder JM and Brown DR: Detection of multiple human papillomavirus types in the lower genital tract correlates with cervical dysplasia. J Med Virol 64: 550-559, 2001.

37. Trottier H, Mahmud S, Prado JC, Sobrinho JS, Costa MC, Rohan TE, Villa LL and Franco EL: Type-specific duration of human papillomavirus infection: Implications for human papillomavirus screening and vaccination. J Infect Dis 197: 1436-1447, 2008.

38. Perrons C, Jelley R, Kleter B, Quint W and Brink N: Detection of persistent high risk human papillomavirus infections with hybrid capture II and SPF10/LiPA. J Clin Virol 32: 278-285, 2005.

39. Zhao R, Zhang WY, Wu MH, Zhang SW, Pan J, Zhu L, Zhang YP, $\mathrm{Li} \mathrm{H}, \mathrm{Gu}$ YS and Liu XZ: Human papillomavirus infection in Beijing, People's Republic of China: A population-based study. Br J Cancer 101: 1635-1640, 2009.

40. Lai CH, Chao A, Chang CJ, Huang CC, Wang LC, Hsueh S, Lin CT, Wu TI, Jao MS and Chou HH: Age factor and implication of human papillomavirus type-specific prevalence in women with normal cervical cytology. Epidemiol Infect 140: 466-473, 2012.

This work is licensed under a Creative Commons Attribution-NonCommercial-NoDerivatives 4.0 International (CC BY-NC-ND 4.0) License. 